\title{
Aid and Governance: Doing Good and Doing Better
}

\section{Aaron Schneider}

Will more aid help developing countries? The answer to this question depends on our view of states in developing countries. Two views prevail. One view sees aid undermining government accountability to citizens, propping up autocratic regimes and disappearing into the pockets of corrupt officials. Another perspective sees aid contributing crucial fiscal and administrative capacity that helps governments better serve their people. In fact, neither view is entirely right (or wrong). Increasing aid enhances government capacity up to a point, but aid can undermine legitimacy if it undermines state accountability to citizens.
The cross-national statistical evidence shows that increasing aid improves government capacity, though the relationship starts to tail off at levels higher than approximately 40 per cent of the Gross Domestic Product (GDP). The same data also shows that donor fragmentation contributes to government incapacity. A close case study of Mozambique confirms and deepens our understanding of these processes. In Mozambique, improved donor coordination and higher volumes of aid helped to increase capacity, reduce transaction costs for government and increase the government's accountability.

Figure 1: Aid Substituting for Domestic Partnerships

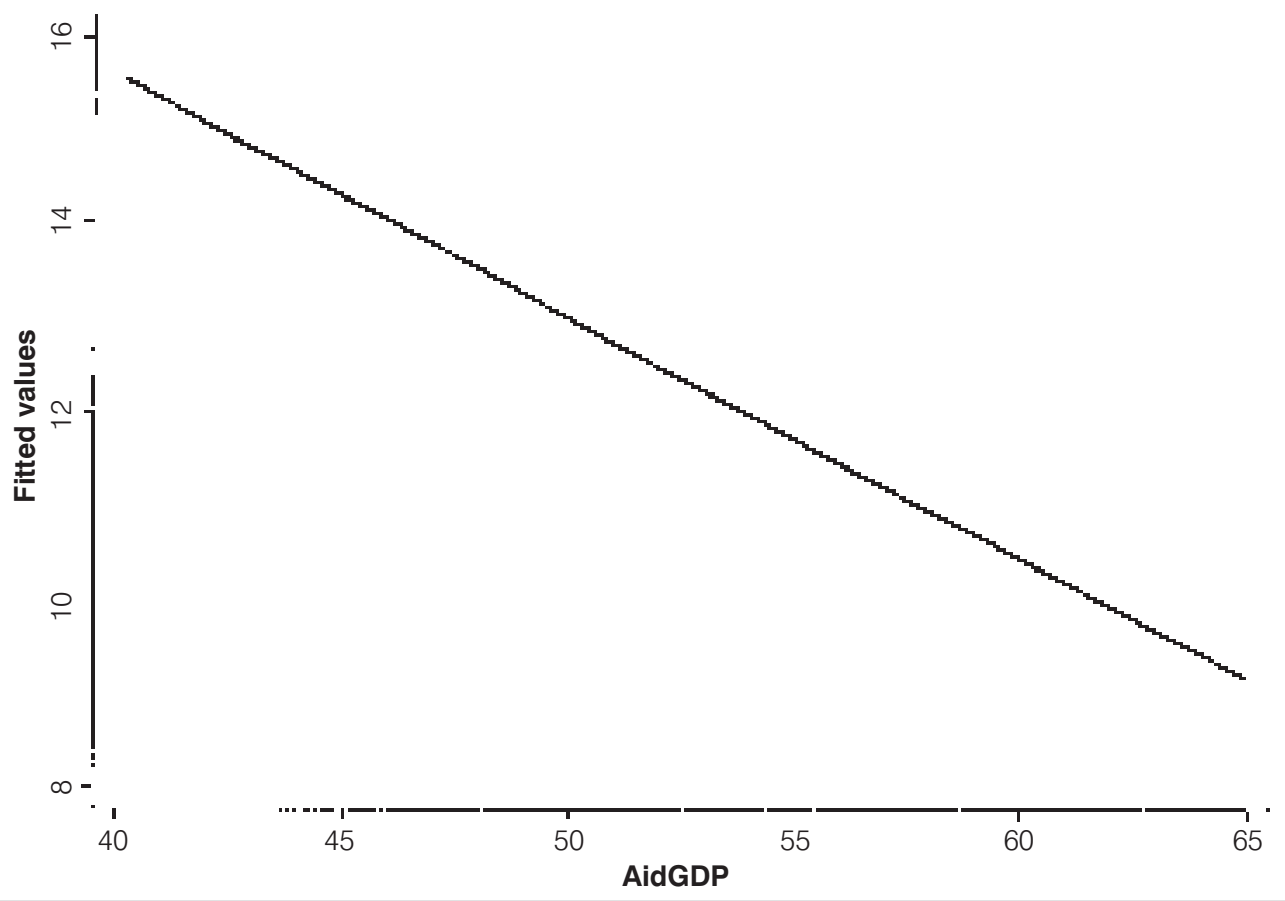

IDS Bulletin Vol 36 No 3 September 2005 (C) Institute of Development Studies 
Figure 2: Aid Enhancing Government Capacity

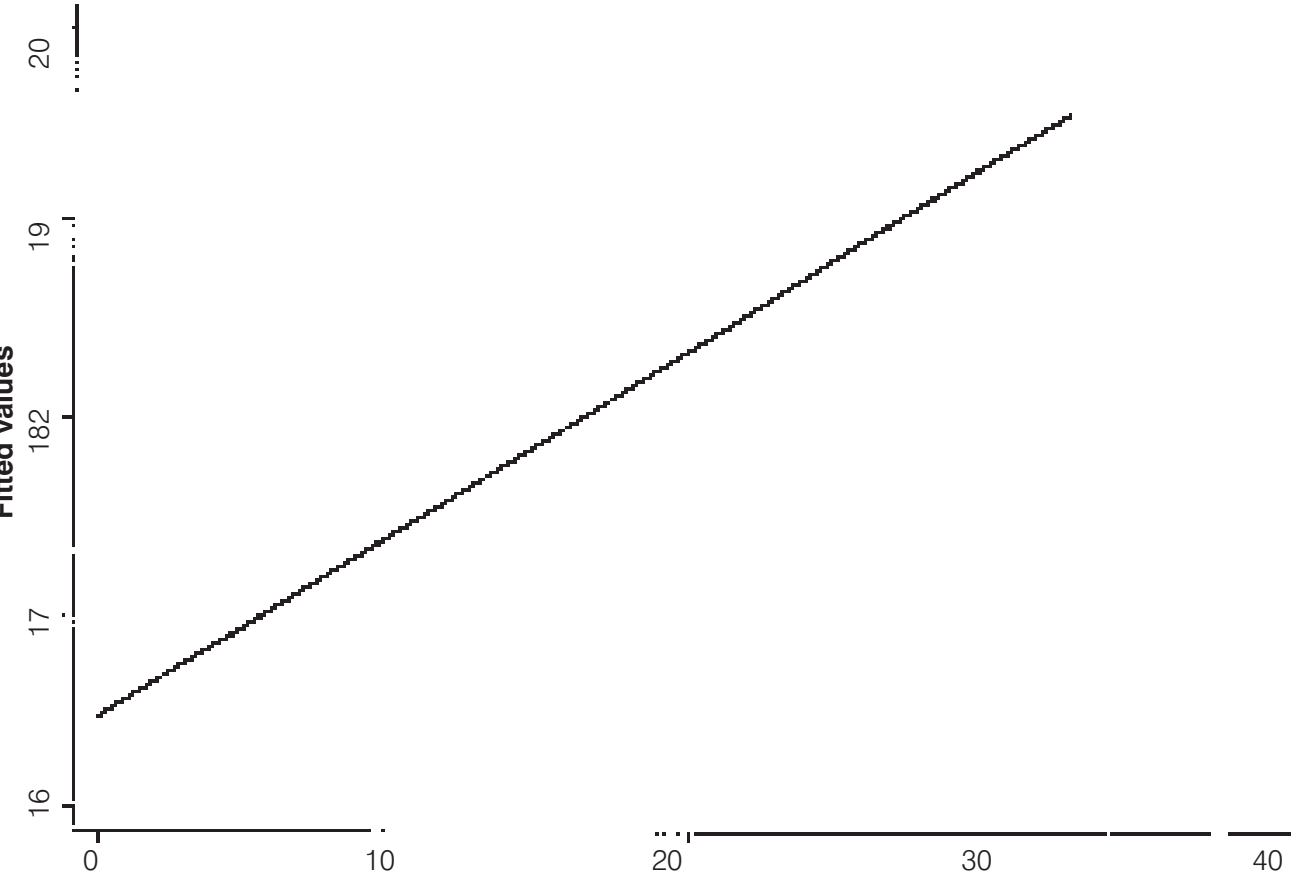

AidGDP

To make these points, the current article uses cross-national statistical evidence and that case study. Cross-national statistical data was available for the 1980s and 1990s from International Monetary Fund (IMF) Government Finance Statistics and Organisation for Economic Cooperation and Development (OECD) Development Assistance statistics. Both sources are fairly reliable and consistent, though the country coverage is less than desirable. Nevertheless, panels of at least 105 countries are available for most years. To analyse the data, dynamic panel data analysis compared evidence across countries and over time. ${ }^{1}$ The main variables included in the analysis were the volume of aid, donor fragmentation and tax effort. ${ }^{2}$ The analysis of Mozambique was taken from a Department for International Development (DFID)funded study in which the author had a role (Hodges and Tibana 2004).

\section{Aid and the state}

The results obtained here follow from competing and potentially contradictory notions of developing country states. These notions provide an elegant tension between those who would emphasise state legitimacy and those who would emphasise state capacity. As most observers recognise, both legitimacy and capacity are core characteristics of governance (DFID 2005).

The first statistical result follows from theories of the state that focus on legitimacy. According to these theories, states are (or ought to be) partners with society. Together, they create a social contract in which rulers and the ruled negotiate over revenues, representation and services. ${ }^{3}$ If the state does not depend on citizens for revenues, however - as in the case of natural resource rich, or highly aid-dependent states - the social contract is severed.

If governance depends on a social contract, we would expect a downward slope when we predict tax effort. Social contracts should be stronger at lower levels of aid, ceteris parabis, but should decline as aid substitutes for domestic partnerships. This appears to be the case for aid above 40 per cent of the GDP. At high levels, an increase in aid produces a decrease of tax effort.

On the other hand, an alternative view sees rulers as maximisers. To the best of their ability, rulers 
Figure 3: Aid and Governance

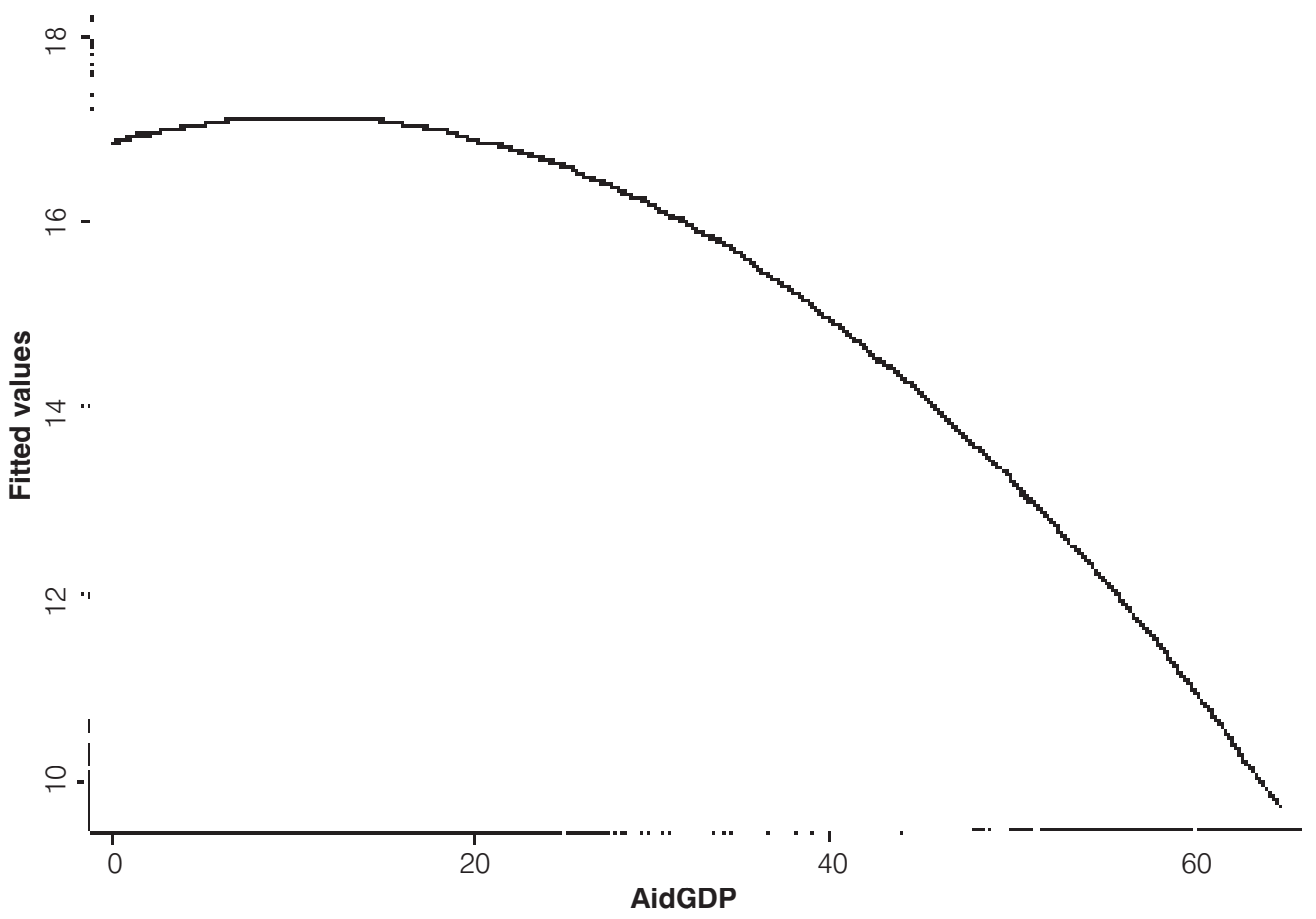

respond to their citizens. ${ }^{4}$ The main constraint they face is not the strength of social contracts, but rather the capacity of the state. Public administrations with more resources, better technologies and improved training do more than weak states.

From the state capacity perspective, we would expect an upward sloping curve when we predict tax effort. As aid increases, capacity should increase. In fact, up to around 35 per cent of the GDP, an increase in aid does create an increase in tax effort.

The point of these two figures is to say that there is no single answer to the aid and governance relationship. More aid increases government capacity up to a point, but it cannot be allowed to undercut social contracts with domestic actors. The overall relationship between aid and governance, therefore, is curvilinear. As aid volumes increase, tax effort increases, but beyond a certain level, tax effort begins to taper.

The key is apparently to increase capacity without undercutting social contracts. One of the causal mechanisms by which aid might undercut social contracts is by increasing the transaction costs of revenues. Accepting aid means recipient governments must allocate staff for meetings, comply with priorities on where to spend, manage funds according to procedural conditions and report their results. High levels of aid frequently come with high numbers of donors, who follow each other in a herd to the newest and latest developing country favourite. The proliferation of donors that ensues increases the burden on governments. They use up scarce resources and time to negotiate and comply with donors; salaries are driven upwards; and the most capable bureaucrats are poached by high-paying donor consultancies. The sheer volume of money and donors means that governments end up being more accountable to donors and less accountable to their own citizens or to internal government accountability mechanisms such as parliamentary oversight (Bräutigam 2000).

Other things being equal, we would expect that high levels of donor fragmentation would weaken government capacity. The measurement of donor fragmentation is possible using an index of concentration adapted from an index used to 
Figure 4: Transaction Costs and Governance

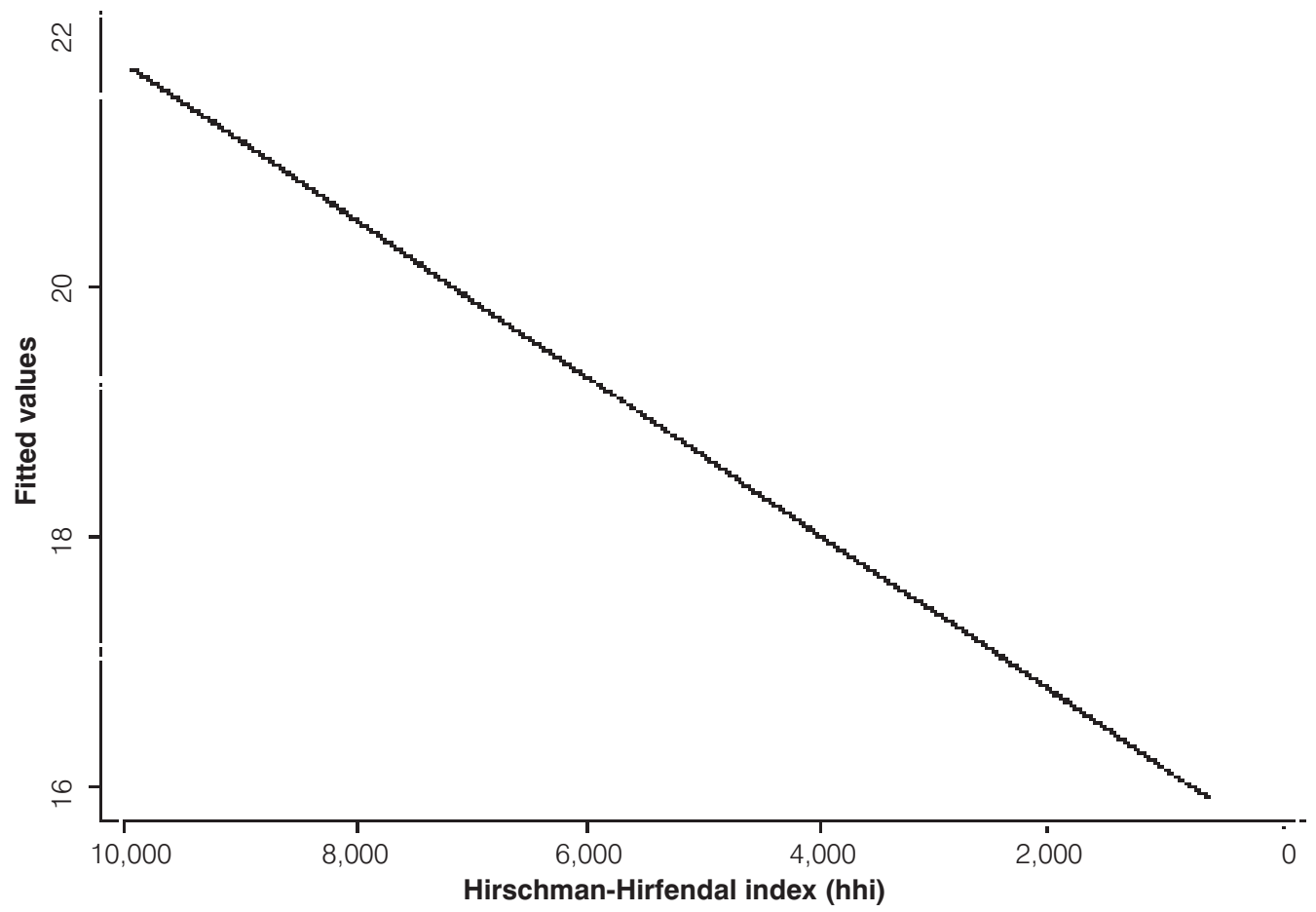

calculate the degree of concentration of firms in the industrial sector. As expected, the impact of fragmentation on tax effort is a downward slope. More fragmentation weakens governance.

These statistical comparisons suggest quite powerful results. Volumes of aid have a direct relationship with governance in developing countries, and so does donor behaviour. As aid volumes increase, it contributes to government capacity to serve citizens. Yet aid flows can undercut the social contract between state and society by substituting for government revenues or imposing excessive transaction costs on government. Thus, donors bear some responsibility for the quality of governance in the South - more specifically - while donors should increase volumes to a point, they should also improve their behaviour.

\section{Making aid better: Mozambique ${ }^{5}$}

Mozambique is a classic case of aid dependence. Since the end of civil war in 1992, donors have offered massive aid to improve government capacity, support development projects, and ensure peace.
In recent years, flows of aid have been equal to approximately half of public expenditure; and in some sectors such as health (69 per cent) and roads and water ( 75 per cent), external support accounted for even higher proportions.

\subsection{The problem}

The massive inflow of aid has provided necessary capacity and pushed forward reforms that strengthen public sector institutions, improve the climate for private investment and promote growth. On the other hand, aid has damaged governance by undercutting accountability relationships and state capacity. Accountability is undermined by the impression that policies belong to donors and not to government or society. Capacity is undermined by the volatile and unpredictable flows of aid that are encumbered by a confusing array of conditions, procedures and reporting requirements.

The particular aid modality that has been dominant in Mozambique as in most parts of Africa is project assistance. Project assistance is usually negotiated directly between donors and line 


\section{Figure 5: General Budget Support in Mozambique. Internal and External Budget Resources, 2003 (\% of total resources)}

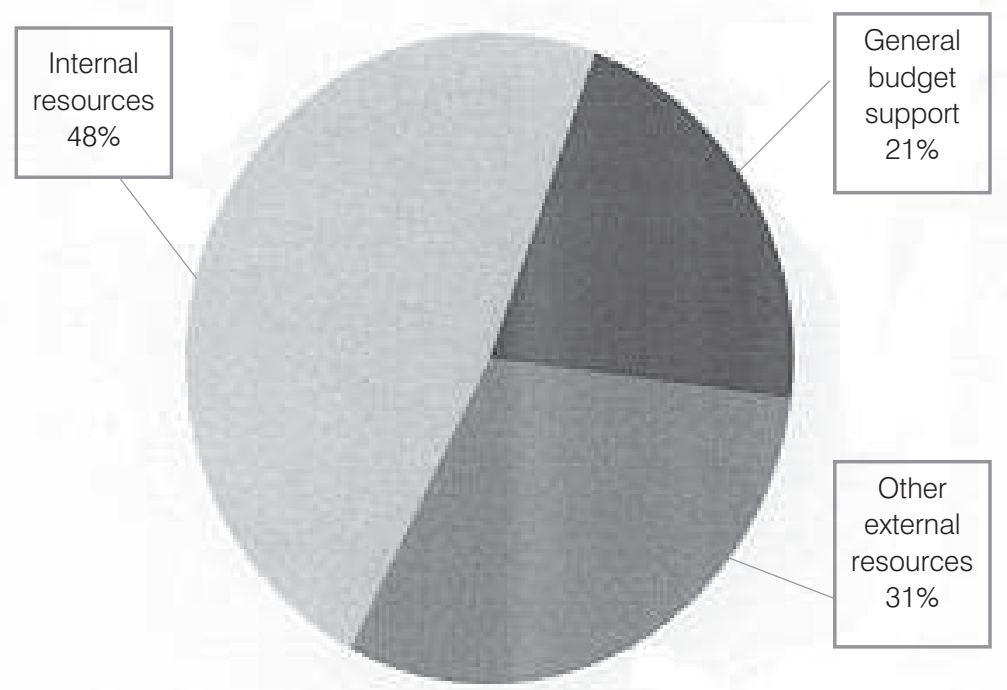

Source: Mapa fiscal, MPF, June 2004.

ministries, or individual directorates or departments within them. Often, projects are associated with special project units that are poorly integrated into existing directorates or departments of ministries. These units poach personnel by paying salaries far higher than normal civil service scales and operate according to independent schedules. The funds disbursed are often off-treasury, if not entirely offbudget.

The implications of project assistance for accountability are severe. Line ministries lose their ability to manage sector-wide development strategies as individual departments obtain greater autonomy. In turn, ministries of finance and parliament lose their ability to control and oversee aggregate government activity.

The capacity implications are no less dramatic. The various donors introduce multiple conditionality frameworks, management arrangements and reporting requirements. The fragmented array of projects disconnects planning, budgeting and implementation, thus weakening public finance management processes that are already weak. Each project draws time, personnel and resources away from mainstream activities, and those civil servants that remain in normal jobs suffer from limited resources, a sense of comparative deprivation and low morale.
The emergence of common funds has helped to mitigate some of these negative effects. Donors pool their resources and establish a common framework for reporting and reviewing performance, often across an entire sector. Line ministries receive untied resources and ideally, these resources are completely on-budget.

Unfortunately, even common funds have left some problems unresolved. Some replicate the deficiencies of project financing, acting simply as multi-donor project facilities or "basket funds", with some or all of the traditional vices of separate project units, distorting salary levels and off-treasury payment mechanisms. Ultimately, even sector-wide common funds introduce rigidities and crowd out other priorities. Domestic allocation decisions and processes become sidelined as sector programmes absorb most of the budget.

\subsection{Doing better}

In response, many donors have begun to provide general budget support (GBS). Though fiduciary risks exist, the potential benefits include governmentwide ownership of the planning and resource allocation process, strengthening domestic accountability to parliament, and reducing transaction costs associated with aid. In Mozambique, 
GBS has expanded to encompass 15 donors (14 bilateral donors plus the World Bank), who are now known as the G15 Programme Aid Partners (PAPs). Total GBS was US $\$ 297 \mathrm{~m}$ in 2002 and US $\$ 277 \mathrm{~m}$ in 2003. These figures include GBS grants from bilateral donors (US\$175m in 2003) and loans (US\$92m in 2003) - with Heavily Indebted Poor Countries (HIPC) debt relief as a further benefit. (Multilateral agencies - especially the World Bank and the African Development Bank - provided GBS outside the common donor framework, though it has been incorporated for 2004.)

GBS is linked to a government and donor dialogue that occurs in two meetings each year. In these encounters, government and donors negotiate the terms by which performance is to be assessed and the latter commit to aid contributions. The first meeting reviews previous performance, and donors follow with their commitments for the following year. In the second meeting, donors and government set the framework for assessing future performance and agree a disbursement schedule before the start of the fiscal year.

The agreement between donors and government, formally labelled a Memorandum of Understanding, includes a "response mechanism" that establishes a link between performance, commitments and disbursements.

\section{Improved accountability}

GBS changes accountability relationships in several ways. The dialogue between government and donors establishes an assessment framework based on targets and indicators that are regularly updated and agreed among the Ministry of Finance, line ministries and donors. Such explicit priority targets create more transparent and consensual evaluation measures. These fall short of formal conditionality for most donors and government now counts on relatively predictable disbursements of funds.

Within government, the emergence of GBS has also partially reconfigured accountability relationships. GBS funds are automatically ontreasury and untied, adding to the resources available for allocation in the budget formulation process. This increases the role of the Ministry of Finance within the budget process, increases the potential link between plan, budget and implementation and potentially enhances parliament's ability to oversee public intentions through the budget process.
The increased role of the Ministry of Finance also correlates with decreased autonomy of the line ministries. They no longer receive as many funds directly from donors, and increasingly they have to depend on parliamentary and intra-governmental processes to secure funds from the annual budget and the government payment system. This can be associated with greater insecurity and volatility of funds for individual ministries, though as a whole it encourages greater coordination among ministries and closer links between planning directorates and the Ministry of Finance.

\section{Improved capacity}

In addition to changing accountability relationships, some of the most significant impacts of GBS are in the area of state capacity. GBS includes specific investments in personnel and infrastructure capacity for the planning and budgeting system. The hope is that technology and capacity transfer can improve links between stages of the budget cycle and regularise disbursal of funds within the government accounting system.

The dialogue between donors and government further assists government capacity. As a result of the meetings and the explicit principles of the system established, programme aid is brought closer to Mozambican instruments, processes and systems of financial management. This assists government in coordinating flows with domestic budgetary and planning cycles and avoids some of the duplication of duties that occur in long-term planning, budgeting and implementation for aid programmes and ordinary budgeting.

The dialogue and consensual agreement of conditions allows donors to harmonise their procedures, monitoring and reporting. This greatly decreases the compliance costs for government and cuts the uncertainty related to multiple donor requirements. The conditions themselves can be built into the capacity-building effort and structured around platforms of improved financial management.

\section{Remaining issues}

Despite the improvements, several accountability and capacity constraints still trouble the authorities in Mozambique. The main beneficiary of the shift in aid modalities is the ministry of finance, but as a result it has found its technical and personnel capacity burdened. Though the donors coordinate 
and limit their interactions to the biannual meetings, each one continues to create significant transaction costs for government, and these costs are now concentrated more intensely on a single ministry. (The line ministries must also prepare for these meetings, and they continue to receive sector and project funds, though at lower levels than before.) So while the main objective of GBS is to put more funds into formal domestic budget processes, it does not eliminate the transaction costs associated with obtaining funds. These costs are now directed towards inter-ministerial and parliamentary budgetary processes.

A genuinely new dynamic in the aid relationship is created by GBS. The change is mainly evident in the bargaining position of government and donors. Already overwhelmed in many respects, government now faces a single front of donors negotiating as a harmonised bloc with massive technical resources. The accountability that emerges through this powerful pressure potentially overshadows accountability to parliament and civil society. In theory, donor performance assessment criteria could be integrated - thus facilitating parliamentary oversight - but this has not yet happened. More commonly, the resulting impression is of the creation of yet another "donor-driven" instrument.

Ultimately, the united donor front introduces the risk of coordinated punishment. Given the weight of GBS within overall government resources, the potential impact of a suspension of GBS would

\section{Notes}

1. For details on the analysis, contact the author a.schneider@ids.ac.uk. The techniques are described in Bond (2002).

2. For a definition and measurement of donor fragmentation, see Acharya et al. (2004).

3. See Bates and Da-Hsiang (1985). Others see the partnership as pernicious; dominant groups use the state as an instrument to subordinate other groups. See Lindblom (1977). be devastating. On the other hand, we may hope that the institution of negotiation and dialogue establishes a mechanism by which such sanctions could be avoided and more cooperative outcomes obtained. For example, in 2001, complications over semi-public banks arose, and a limited number of GBS donors at the time halted payments. Quickly, however, negotiations produced an agreement by which aid could be resumed.

\section{Conclusions}

The evidence presented here supports the general argument that more aid and better donor behaviour can support improved governance in aid recipients. Cross-national statistical evidence demonstrates that tax effort increases with quite significant increases in aid. This is associated with the enhanced capacity that an influx of resources allows. At the same time, this influx of resources cannot be allowed to undercut the accountability relationships that link state to society in a social contract. Massive revenues that substitute completely for domestic sources and high transaction costs that undercut state capacity potentially undermine governance in aid recipients. In Mozambique, high levels of aid enhanced capacity, but transaction costs associated with project aid burdened government. The shift to general budget support by an ever larger number of donors has altered accountability relationships within government and increased government capacity.

4. For a view of rulers as predators who maximise rents, see Levi (1988). For a view of rulers as benevolent dictators who maximise social welfare, see Musgrave and Musgrave (1989).

5. This section is adapted from Hodges and Tibana (2004), section 4.2 . 


\section{References}

Acharya, A., Fuzzo de Lima, A. and Moore, M., 2004, 'The proliferators: transactions costs and the value of aid', IDS Working Paper 214, Brighton: Institute of Development Studies

Bates, R.H. and Da-Hsiang, D.L., 1985, 'A note on taxation, development, and representative government', Politics and Society, Vol 14 No 1: $53-70$

Bond, S.R., 2002, 'Dynamic panel-data models: a guide to micro data methods and practice', CEMMAP Working Paper CWP09/02, London: Centre for Microdata Methods and Practice

Bräutigam, D., 2000, Aid Dependence and Governance, Stockholm: Almqvist and Wicksell International
DFID, 2005, Fighting Poverty to Build a Safer World, London: Department for International Development

Hodges, A. and Tibana, R., 2004, Political Economy of Budgeting in Mozambique, Lisbon: Principia

Levi, M., 1988, Of Rule and Revenue, Berkeley: University of California Press

Lindblom, C., 1977, Politics and Markets, New York: Basic Books

Musgrave, R.A. and Musgrave, P.B., 1989, Public Finance in Theory and Practice, 5th edn, New York: McGraw-Hill 